\title{
Label-free smartphone quantitation of bacteria by darkfield imaging of light scattering in fluoropolymer micro capillary film allows portable detection of bacteriophage lysis
}

Article

Accepted Version

Creative Commons: Attribution-Noncommercial-No Derivative Works 4.0

Dönmez, S. İ., Needs, S. H. ORCID: https://orcid.org/00000003-3407-9637, Osborn, H. M. I. and Edwards, A. D. ORCID: https://orcid.org/0000-0003-2369-989X (2020) Label-free smartphone quantitation of bacteria by darkfield imaging of light scattering in fluoropolymer micro capillary film allows portable detection of bacteriophage lysis. Sensors and Actuators B: Chemical, 323. p. 128645. ISSN 0925-4005 doi: https://doi.org/10.1016/j.snb.2020.128645 Available at https://centaur.reading.ac.uk/92286/

It is advisable to refer to the publisher's version if you intend to cite from the work. See Guidance on citing.

Published version at: http://dx.doi.org/10.1016/j.snb.2020.128645

To link to this article DOI: http://dx.doi.org/10.1016/j.snb.2020.128645

Publisher: Elsevier

All outputs in CentAUR are protected by Intellectual Property Rights law, 
including copyright law. Copyright and IPR is retained by the creators or other copyright holders. Terms and conditions for use of this material are defined in the End User Agreement.

\section{www.reading.ac.uk/centaur}

\section{CentAUR}

Central Archive at the University of Reading

Reading's research outputs online 


\title{
Label-Free Smartphone Quantitation of Bacteria by Darkfield Imaging of Light Scattering in Fluoropolymer Micro Capillary Film Allows Portable Detection of Bacteriophage Lysis
}

\author{
Sultan İlayda Dönmez ${ }^{1}$, Sarah H. Needs ${ }^{1}$, Helen M.I. Osborn ${ }^{1}$, Alexander D. Edwards ${ }^{1 *}$
}

${ }^{1}$ School of Pharmacy, University of Reading, Whiteknights, Reading, RG6 6AD, UK.

*Corresponding author a.d.edwards@reading.ac.uk +44 1183784253

Key word list; Label-free detection, Light scattering, Bacteria, Microfluidic, Bacteriophage, Smartphone diagnostics

\section{Highlights}

-Darkfield imaging allows quantitation of bacterial cells by smartphone without dye -Label-free bacterial imaging permits direct observation of growth kinetics and sedimentation

-Host specificity of bacteriophage can be detected by smartphone in $1.5 \mathrm{~h}$, with lysis complete in $4 \mathrm{~h}$

- Sensitivity with smartphone detection similar to spectrophotometer

\begin{abstract}
Conventional methods for the detection and quantitation of bacteria are slow, laborious and require a laboratory. Microfluidic systems offer faster and portable testing, and smartphone cameras can record colorimetric or fluorometric bioassays, but this requires dye addition. Here, we demonstrate for the first time label-free smartphone detection of bacterial light scattering by darkfield microfluidic imaging to measure bacteria and bacteriophage lysis. A single LED and portable 3D printed imaging box allowed bacterial concentration and growth to be measured by direct imaging of bacterial light scattering. Bacteriophage lysis was detected within a 10-channel microfluidic device made from melt-extruded fluoropolymer micro capillary film, allowing rapid detection of host specificity. Elimination of unwanted reflections and optimising illumination angle are critical for successful darkfield bacterial imaging, with $15^{\circ}$ giving maximal intensity. Bacterial sedimentation was directly observed within microfluidic devices, and detection sensitivity significantly increased
\end{abstract}


by allowing bacteria to sediment for 30 minutes. With this simple, low-cost, 3D printed system bacterial concentrations down to an optical density of 0.1 could be measured corresponding to $8 \times 10^{4}$ colony forming units (CFU) per microdevice, approaching the sensitivity of conventional spectrophotometers. Bacteriophage lysis could be detected at a range of starting cell concentrations. With a low starting cell concentration, the increase in light scatter signal with incubation was prevented in the presence of bacteriophage. Conversely, with high starting cell concentration, the light scatter signal detected at the start was clearly eliminated when phage were added, indicating this simple system allows direct visualisation of bacteriophage eliminating light scattering by lysis.

\section{Introduction}

Antimicrobial resistance (AMR) is a major global challenge as antibiotic resistance becomes more prevalent, for example due to microorganisms exchanging resistance genes, and more complex resistance mechanisms, such as biofilm formation, are identified. This makes it harder to treat bacterial infections (WHO, 2014) and it is estimated that by 2050, 10 million people could die annually as a consequence of AMR (Kraker, 2016). To tackle this challenge, alternative antimicrobials are essential, and improved tools for rapid microbial detection and antibiotic susceptibility testing are needed to inform antibiotic selection using surveillance and diagnostics (van Belkum et al., 2019). Lytic bacteriophages, which are diverse viruses that replicate whilst killing specific bacteria, are not affected by common antibiotic resistance mechanisms and hence are valuable alternatives to antibiotics (El Haddad et al., 2018, Debarbieux et al., 2010, Altamirano and Barr, 2019). However, therapeutic phages can only be effective if the infectious agent is a susceptible host, so new methods for rapid determination of bacterial lysis by phage are needed. The traditional double agar layer bacteriophage detection method takes around 24-48 $\mathrm{h}$ to complete. Suspensions of phage and host bacteria are combined in agar, with the solid medium limiting the spread of bacteria and phage such that clear plaques can be detected after overnight incubation representing areas where phage have lysed a layer of bacteria.

Bacteriophage have been exploited in the search for rapid and sensitive bacterial detection (Farooq et al., 2018). Lytic T7 bacteriophage attached to magnetic beads were used to detect $E$. coli in drinking water, providing colorimetric detection via a $\beta$-galactosidase substrate within $2.5 \mathrm{~h}$ $\left(10^{\wedge} 4 \mathrm{cfu} / \mathrm{ml}\right)$, but in order to detect fewer bacteria $(10 \mathrm{cfu} / \mathrm{ml}), 6 \mathrm{~h}$ of pre-enrichment is required. (Chen, 2015). Lytic phage progeny were also detected via $\beta$-galactosidase activated fluorescent probes, allowing phage enumeration with a plaque-droplet assay, cutting detection time to 90 minutes (Tjhung et al., 2014). Bacteriophage lysis can also be measured by changes in media impedance following lysis, allowing $E$. coli detection via a screen-printed carbon electrode and immobilized T4 bacteriophage (Shabani, 2013). Lytic bacteriophages were used as a signal amplification method for detection of Bacillus anthracis using lateral flow immunochromatography 
(Cox et al., 2015). Enzyme-tagged phage allow rapid E. coli enumeration in drinking water either colorimetrically on filters (Hinkley et al., 2018), or electrochemically (Wang et al., 2019), and droplet microfluidics allow direct observation of bacteriophage lysis (Yu et al., 2014).

Smartphone cameras have been exploited to digitally record and quantify colorimetric and fluorometric bioassays outside the lab (Huang et al., 2018) and smartphone bacteriophage detection would allow near-patient testing. However, bacteriophage have a different mechanism of action on bacteria compared with antibiotics, so conventional antibiotic susceptibility testing methods (disc diffusion/broth microdilution) cannot be used. Phage lysis is typically detected by turbidity measurement and enumerated with plaque assays on solid media, in the double agar layer (DAL) method. Both these methods require significant user time to complete and the DAL method requires overnight incubation.

Neither is ideally suited to colorimetric or fluorometric smartphone detection, so label-free smartphone bacteria measurement is preferable. Bacterial cell suspensions are most commonly quantified in routine microbiology methods without using dyes, instead relying on visible light attenuation by light scattering in a spectrophotometer. 'Turbidity' is typically measured at $600 \mathrm{~nm}$ and expressed as Optical Density (OD). Bacterial cells tend to be largely colourless but contain multiple structures with transitions in refractive index (e.g. cell wall), and therefore suspensions of bacteria tend to scatter light rather than absorb it. In contrast to absorbance measurements of solutions of compounds at specific wavelengths, light scattering by bacteria is largely independent of wavelength across the visible light range, resulting in a milky white appearance and a similar OD at differing wavelengths (Myers et al., 2013, McBirney et al., 2016). This laboratory technique is not especially sensitive and a standard measurement range for spectrophotometers with a $1 \mathrm{~cm}$ pathlength cuvette is an OD of $0.1-1 \mathrm{~cm}^{-1}$ where there is a linear relationship between cell concentration and OD. However, in spite of the narrow dynamic range of bacterial cell measurement by turbidity, and high cell concentration required - with an OD of 0.1 corresponding to around $10^{8} \mathrm{CFU} / \mathrm{mL}$ (Myers et al., 2013) - it remains ubiquitous because so many analytical microbiology methods use cell concentrations in this range.

Instead of measuring the attenuation of collimated light as OD in a spectrometer, bacterial light scattering can also be measured as an increased positive signal. Light scatter by bacteria has been measured multiple ways. The angle and intensity of light scatter from colloids is affected by particle size, but the complex composition of bacteria makes light scattering by these heterogenous particles - containing multiple structures with mixed refractive index - more difficult to model than with more uniform colloids. For example, flow cytometry routinely measures light scatter on an individual cell level at two angles, allowing some different species to be distinguished by differences in these two values even without dyes or staining. Forward scatter is generally associated with overall cell size and side scatter indicates granularity of cell contents (Felip et al., 2007, Shvalov et al., 1999). Particle sizes larger than the wavelength of the incidence light result in 
Mie scattering with greater amount of forward scatter (low angle scatter) and for uniform particles information about particle size can be gained from the intensity variation with scatter angle. This has been used for bacterial detection (Waltham et al., 1994, Jo et al., 2015, Hussain et al., 2019), and identification of bacteria directly on skin (Sweeney et al., 2017). In contrast, for particles smaller than the incident wavelength Rayleigh scatter is more prominent with more intense scattering at larger angles. Laser nephelometry measures light scatter by a wide range of biological colloids with an intense coherent bean of incident light, including very small biological particles such as antibody-antigen complexes. Laser nephelometry has also been used for the detection of microorganisms. While forward scatter would provide the most sensitivity, this can be difficult to measure as the detector cannot distinguish the intense incidence light from the scattered light; therefore a detector is usually placed at $90^{\circ}$ to the incident laser (Hoppensteadt and Molnar, 2020). .

Because light scattering can be recorded by digital imaging it is therefore ideal for analysis outside the laboratory by making use of the latest generation of low-cost optoelectronics, such as a smartphone camera combined with LED illumination. Such portable digital imaging has be combined with microfluidic devices to offer further benefits, as miniaturisation into microdevices not only provides a portable format but can also decrease assay times compared to conventional laboratory-based bioassays.

Melt- extruded microcapillary film (MCF) with 10 parallel capillaries can be easily and costeffectively turned into multiplex bioassay strips suitable for microbial detection (Reis et al., 2016a, Alves and Reis, 2019b, Needs et al., 2019). Microfluidic devices are commonly made of polymers with a different refractive index to water, which can complicate use of imaging techniques such as quantitation of light scattering as light can be refracted or reflected at the device-sample interface (Polanco et al., 2018). In contrast, MCF made from fluoropolymer fluorinated ethylene propylene (FEP) has a refractive index matching water, minimising optical background by diffraction or reflection at the sample-device interface, allowing sensitive colorimetric and fluorometric bioassays (Edwards et al., 2011, Barbosa et al., 2015, Alves and Reis, 2019b, Needs et al., 2019, Reis et al., 2016a). Here we show for the first time that this exceptional transparency also makes label-free bacterial detection by darkfield imaging of light scattering in a microfluidic device feasible. Light scattering by bacteria was recorded within MCF test strips by digital imaging including smartphone camera imaging illuminated with a single LED. Bacterial cell concentration could be quantified over the ranges typically measured in microbiology labs by absorbance in a spectrometer. To illustrate use of this tool we demonstrate that important analytical microbiology methods can be performed in this portable and miniaturised system by showing that bacterial growth kinetics and bacteriophage lysis can be directly monitored without specialised equipment, using microfluidic devices, a bespoke 3D printed box, illuminated by a single LED, and captured with a smartphone camera. 


\section{Experimental}

\subsection{Materials}

MCF was produced from FEP by Lamina Dielectrics Ltd (Billingshurst, West Sussex, UK) with external dimensions of $4.3 \mathrm{~mm}$ wide and $0.4 \mathrm{~mm}$ thick, and contained 10 capillaries each with an internal diameter of $200 \mu \mathrm{m}$. To produce hydrophilic test strips, $1 \mathrm{~m}$ batches were internally coated by incubation with $5 \mathrm{mg} / \mathrm{mL}$ polyvinyl alcohol (PVOH) solution in ultrapure water, as previously described (Reis et al., 2016a). Cameras included smartphone cameras iPhone 6S and Xperia model L1 (Sony), compact camera S120 (model DS126621, Canon) and digital SLR EOS 1300 with 18 megapixel sensor and an EF-S f/2.8 Macro Lens (Canon). 3mm and 5mm through-hole white LEDs with forward voltage of $3.4 \mathrm{~V}$ and forward current of $20 \mathrm{~mA}$ were from RS Components Ltd (Northants, UK) and CPC Farnell (Leeds, UK) powered with a 5V USB power bank (Amazon UK) and $68 \Omega$ resistor in series; several different LED components were compared including single colour and white LEDs, but the LED type was found to make no significant difference to the light scatter intensity. LB broth and LB agar media were from Sigma (Dorset UK). E. coli reference strain ATCC 25922 was obtained from LGC Standards (Middlesex UK). E. coli B strain was obtained from the National Centre for Biotechnology Education, University of Reading (Reading, UK) and bacteriophage T2 was obtained from Mojgan Rabiey, School of Biological Sciences, University of Reading (Reading UK).

\subsection{Darkfield Imaging System Design and Optimization}

To achieve darkfield imaging and allow dye-free detection of bacteria inside MCF through light scattering from bacterial cells, an initial optimisation process utilised a simple box enclosing key components comprising: light source (LED), sample (MCF test strip), blockers (for blocking unscattered light directly from the LED) and a camera or smartphone (Figure 1).

The simple LED light-source was chosen as a low-cost and accessible component. A collimated light-source may help to increase sample illumination intensity or reduce glare caused by incoherent light reflecting on the surfaces of the 3D printed prototype, increasing the signal:noise ratio. By reducing the unwanted light, it may also be possible to image the device at a lower angle increasing the scattering intensity. Similar readers to detect light scatter have used an opaque rod at the focal plane to block direct laser light from the detector in a low angle detection scheme (Sun et al., 2019).

MCF test strips loaded with either water alone or differing concentrations of non-viable E. coli cells (inactivated by $70 \%$ ethanol, 15 minutes). The relative positions of the light source and sample were altered to determine optimal parameters for bacterial detection, ranging from: LED illumination angles $5^{\circ}$ up to $25^{\circ}$; LED to sample distance 100 to $200 \mathrm{~mm}$; LED colours of white, blue, green and red; camera distances 100 to $200 \mathrm{~mm}$. We also examined the microfluidic device orientation: firstly, the capillary orientation was varied (vertical vs horizontal) to study the effect of 
gravity on the bacterial sample; and secondly the device orientation with respect to illumination angle was varied by comparing images with the LED offset by $15^{\circ}$ in a plane with the test strip and capillaries, vs the LED offset by $a 5^{\circ}$ angle about the capillary axis. Finally, the camera type was examined with images taken in parallel using digital SLR, compact digital camera, iPhone 6S and low-cost Android smartphone (Sony Xperia L1). Tested parameters are shown in Table 1.

Table 1. Imaging parameters tested. Underlined parameters indicate optimised system.

\begin{tabular}{|c|c|c|c|}
\hline Parameter & Range tested & Optimal condition & Comment \\
\hline $\begin{array}{l}\text { LED distance to } \\
\text { sample }\end{array}$ & $\begin{array}{l}70 \mathrm{~mm}, 80 \mathrm{~mm}, 90 \mathrm{~mm}, 100 \mathrm{~mm}, \\
110 \mathrm{~mm}\end{array}$ & $90 \mathrm{~mm}$ & $\begin{array}{l}\text { As LED is moved } \\
\text { closer to sample, } \\
\text { glare and } \\
\text { background light } \\
\text { increases }\end{array}$ \\
\hline Illumination angle & $5^{\circ}, 10^{\circ}, 15^{\circ}, 20^{\circ}, 25^{\circ}$ & $15^{\circ}$ & $\begin{array}{l}\text { Lower angles give } \\
\text { higher signal but } \\
\text { higher noise }\end{array}$ \\
\hline $\begin{array}{l}\text { Relative angle of } \\
\text { device to light } \\
\text { source }\end{array}$ & $\begin{array}{l}\text { In plane of capillary axis vs } \\
\text { offset from capillary axis }\end{array}$ & $\begin{array}{l}\text { Illumination offset } \\
\text { in plane with MCF } \\
\text { test strip axis }\end{array}$ & $\begin{array}{l}\text { Reduces reflections } \\
\text { from curved edge of } \\
\text { MCF test strip }\end{array}$ \\
\hline $\begin{array}{l}\text { Camera to } \\
\text { sample distance }\end{array}$ & $\begin{array}{l}150 \mathrm{~mm}, 160 \mathrm{~mm}, 170 \mathrm{~mm}, \\
180 \mathrm{~mm}, 190 \mathrm{~mm}\end{array}$ & $170 \mathrm{~mm}$ & Must \\
\hline LED colour & $\begin{array}{l}\text { Red, green, or blue single colour } \\
\text { LED and white LED }\end{array}$ & $\mathrm{N} / \mathrm{A}$ & $\begin{array}{l}\text { No change in } \\
\text { scatter intensity } \\
\text { with wavelength; } \\
\text { but imaging was } \\
\text { simpler with white } \\
\text { LED }\end{array}$ \\
\hline Camera type & $\begin{array}{l}\text { Canon, S120 (compact digital } \\
\text { camera) } \\
\text { Canon, SLR EOS 1300D with } \\
60 \mathrm{~mm} \text { macro lens (DSLR) } \\
\text { Sony Xperia L1 (Android } \\
\text { smartphone) } \\
\text { iPhone 6S (iOS smartphone }\end{array}$ & $\mathrm{N} / \mathrm{A}$ & $\begin{array}{l}\text { All digital cameras } \\
\text { tested were capable } \\
\text { of capturing images } \\
\text { of scatter; but } \\
\text { manual control of } \\
\text { exposure and focus } \\
\text { is desirable }\end{array}$ \\
\hline
\end{tabular}


With all cameras it was possible to image clear lines showing light scattering by bacterial cells (e.g. Figure 1B) although with some it was easier to control imaging conditions (exposure, focus). The colour of the line depended on the LED colour used for illumination, but no significant difference was found in scatter intensity between different illumination colours. Unwanted light either directly from LED to camera, or from reflections, was blocked by adding black 3D printed frames, or black fabric which had low light reflection. In conventional laboratory microbiology, attenuation by bacterial light scatter decreases the signal intensity from a collimated light-source to a detector placed in direct line from the source through the sample to the detector. Whilst absorbance by dyes can be readily measured within microcapillary film by imaging on a white light background (in spite of the decreased pathlength, $0.2 \mathrm{~mm}$ compared to $10 \mathrm{~mm}$ in a spectrophotometer) (Reis et al., 2016b, Pivetal et al., 2017, Needs et al., 2019), in contrast bacterial light scatter cannot be detected when placed on a white background. Therefore, to detect light scattering the detector is not placed in line with the light source and darkfield imaging is used instead (Hussain et al., 2019). Bacterial cells are roughly 1-3 $\mu \mathrm{m}$ long, larger than the wavelength of visible light, therefore, Mie scattering might be expected, with forward scatter giving the highest intensity. Therefore, the greatest signal intensity should be with the camera in-line with the incidence beam. However, at lower illumination angles it became more difficult for the camera to distinguish light scattered by the sample from light directly from the illumination LED. The camera was kept in line with the microdevice (i.e. orthogonal to the face of the devices) to capture the microdevice architecture fully and ensure the capillaries were all in the same focal plane. The scatter angle was altered by moving the LED to vary the angle of the incident light, and was optimised to increase scatter intensity and reduce capture of unscattered light and unwanted reflections. The smaller the angle of the incidence light the greater the light scattering effect (Figure $1 \mathrm{D}$ ). However, at $\zeta<10^{\circ}$ while the signal increased, the detection of unwanted light also increased, and we selected an optimal illumination angle of $\zeta=15^{\circ}$ as having the optimal signal:noise ratio. 


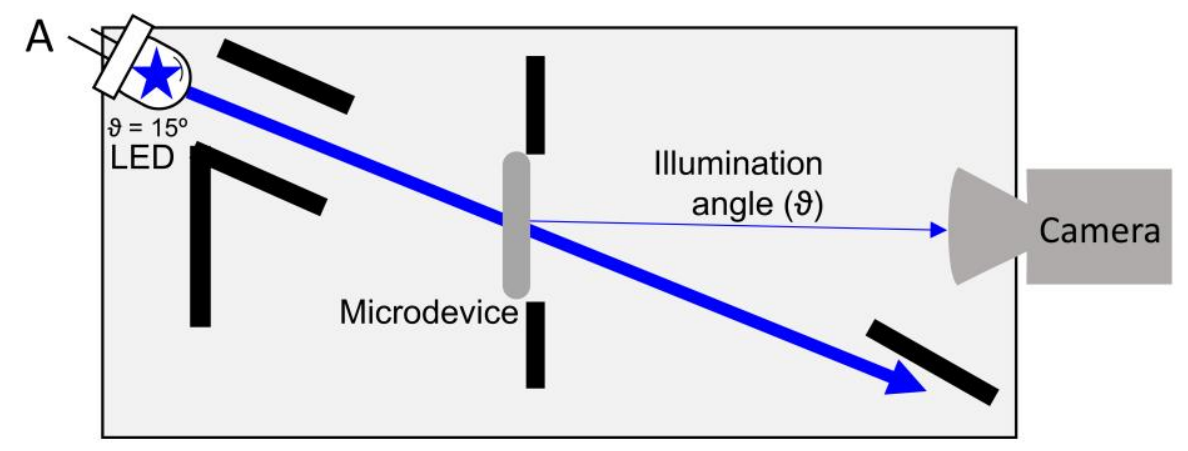

B
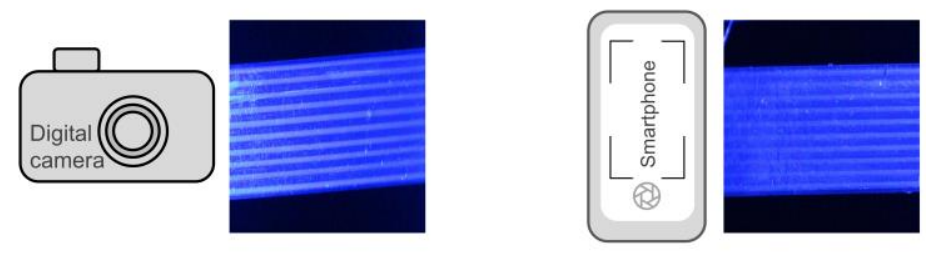

C
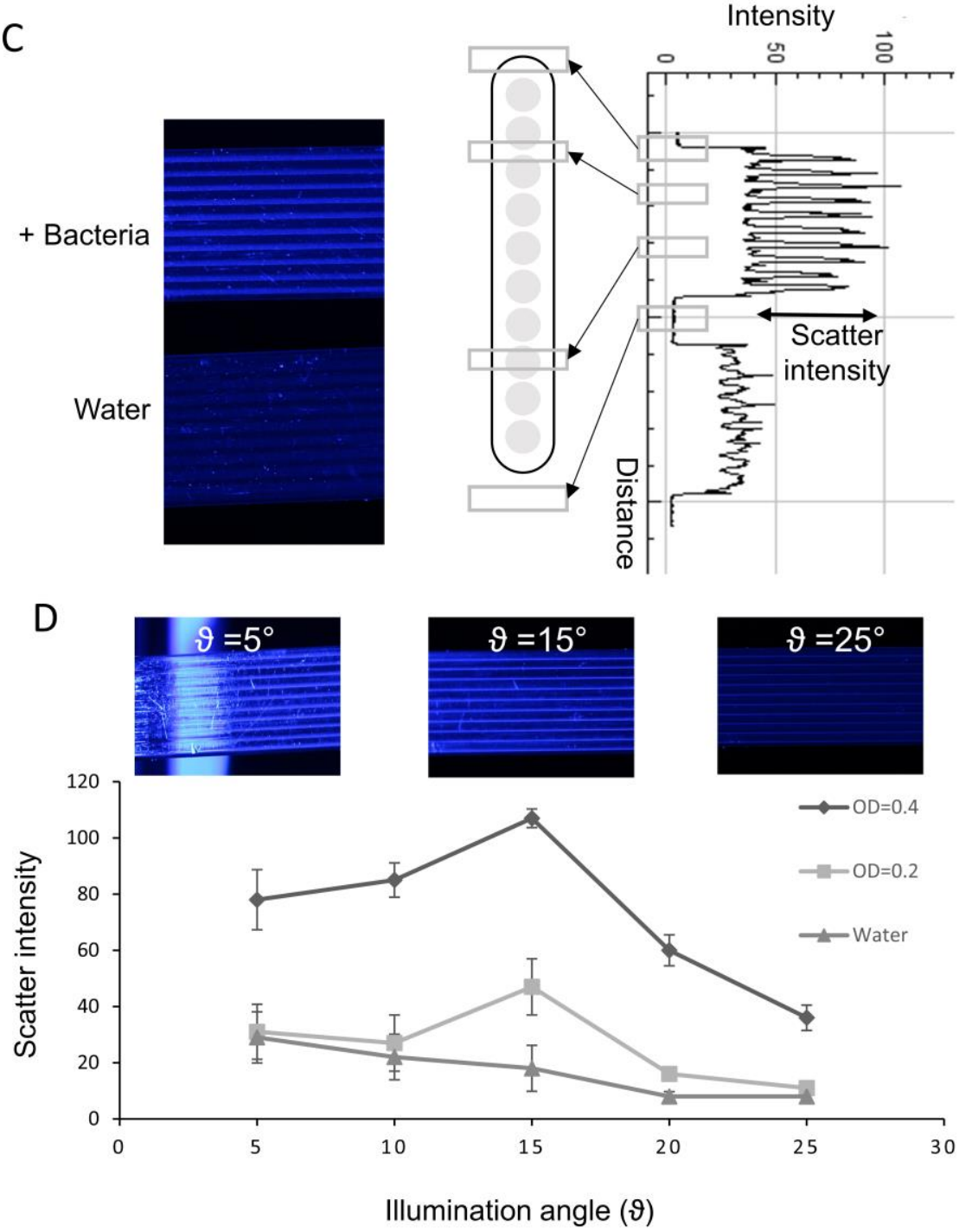

Figure 1: Darkfield imaging allows label-free smartphone detection of bacteria within a microfluidic device. 
A) Geometry of darkfield imaging setup using simple blue LED light source, microfluidic bacterial signal and digital camera. B) Example of bacterial light scattering images taken using camera vs smartphone camera. C) Illustration of image analysis allowing measurement of scatter intensity with an intensity plot across microcapillary device, showing background scatter from microdevice between capillaries. Boxes indicate the following features from top to bottom: reflection from airwater interface at edge of microdevice; light scatter by fluoropolymer device between capillaries; scatter; light scattering by bacteria within capillary; darkfield background. Scatter intensity was defined as the intensity between capillaries to the maximum capillary intensity as indicated. D) Illumination angle was varied and scatter intensity plotted with the indicated 0.2 and $0.4 \mathrm{OD}$ suspensions of killed E. coli and compared to no cells. Although bacterial scatter intensity increased with decreasing illumination angle, at very low angles LED was visible directly and background scatter increased. Scatter intensities plotted indicate means and error bars indicate standard deviation of 10 replicate capillaries. Images presented are representative of at least 5 similar images from independent experiments.

\subsection{Bacteria and bacteriophage preparation and testing}

E.coli B strain and T2 bacteriophage and the non-permissive strain, E.coli 25922 were selected as a convenient and safe model system to study bacteria and phage detection. E.coli $B$ strain was grown in LB broth and agar-media at $37^{\circ} \mathrm{C}$ overnight, a single colony was re-suspended into LB media at OD600 and adjusted to between 0.1 to 1 OD600. For T2 bacteriophage amplification, 2 $\mathrm{ml}$ of an overnight E.coli B strain culture from a single colony isolate was added to $23 \mathrm{ml}$ fresh LB medium and shaken for $3-4 \mathrm{~h}$ at $37^{\circ} \mathrm{C} ; 1 \mathrm{ml}$ of the phage stock was added and incubated overnight, centrifuged at $4500 \mathrm{rpm}$ for $45 \mathrm{~min}$, the supernatant phage suspension was filtered through a 0.22 $\mu \mathrm{m}$ syringe filter and stored at $4^{\circ} \mathrm{C}$.

MCF ribbon was cut to $33 \mathrm{~mm}$ long test strips corresponding to $1 \mu \mathrm{L}$ test volume per capillary. Capillaries were filled with bacteria either by capillary action or injection. To measure detection sensitivity and monitor bacterial sedimentation, ethanol-inactivated bacterial cell suspensions were used at 0.1-1.0 OD600. For growth kinetics, an E.coli colony inoculated in LB medium was incubated at $37^{\circ} \mathrm{C}$ and growth monitored every hour in parallel in a spectrophotometer vs light intensity with darkfield imaging in MCF and bacteria grown in MCF. To determine host cell specificity, E.coli B strain and E.coli 25922 cultures were grown in LB from single colonies. The two bacterial strains were filled at the indicated concentrations into MCF test strips either loaded with or without $\mathrm{T} 2$ phage, and incubated at $37^{\circ} \mathrm{C}$. The MCF capillaries were loaded with phage by filling with a $10^{8} \mathrm{pfu} / \mathrm{mL}$ T2 phage suspension, followed by aspiration of the loading material by syringe, leaving a thin film of bacteriophage suspension on the hydrophilic PVOH surface of the 
microcapillary, as described previously for antibiotic loading (Reis et al., 2016a). Overnight plating was used to determine colony forming units (CFU) for each experiment.

\subsection{Data Analysis}

Digital images were analysed to quantify the light scattering signal using ImageJ (Abràmoff et al., 2004), and the scatter intensity was defined as the difference in light intensity between the space between capillaries and the brightest intensity maximum within each capillary (Figure 1C). Images presented are representative of multiple images and replicate experiments with the number of repeat experiments indicated in the figure legends.

\section{Results and Discussion}

\subsection{Optimising imaging geometry and maximising signal for bacterial quantitation using darkfield imaging of light scatter}

Although turbid bacterial suspensions are clearly visible to the eye, within microcapillaries in MCF, they appear as a grey/white line that was difficult to record with a digital camera. Careful optimisation of the darkfield imaging geometry was needed to maximize the bacterial scattering signal and minimize noise from the illumination LED or unwanted reflections, before bacterial light scattering could be robustly quantified in this way (Figure $1 \mathrm{~A}$ and $\mathrm{B}$ ).

Using optimised geometry, it was possible to clearly distinguish bacterial suspensions from controls without bacteria (Figure 1C). Two major barriers to detecting light scattering by bacteria were identified: firstly when detecting low concentrations of bacteria, the low intensity of signal from bacteria made it hard for the digital camera to focus; secondly bright reflections and unwanted light (termed glare) surrounding the microfluidic device needed to be avoided. The signal was weak with side (side scatter) or epi-illumination (back scatter), and signal:noise varied with illumination angle (Figure 1D). The clearest light scattering images were obtained when samples were illuminated with a light source almost directly behind the MCF at a $15^{\circ}$ angle to the camera, suggesting that forward scatter measurement is most effective(Table 1).

Using the optimal darkfield imaging geometry (illumination angle $=15^{\circ}$; camera to sample distance $=170 \mathrm{~mm}$; LED to sample distance $=90 \mathrm{~mm}$ ) bacterial light scattering was robustly detected. With MCF strips containing water alone, a negative scatter intensity was observed because water-filled capillaries had a lower scattering coefficient than the solid FEP material between capillaries. Reflected and refracted light was seen from the edges of 3D printed blockers, the microfluidic device holder, the surrounding box, and from the microfluidic devices themselves - specifically from its rounded edge and from surface flaws. Reflections from the rounded edge could be minimised by ensuring the LED was offset in line with the MCF test strips rather than rotated around the capillary axis. As expected, LED colour had no significant impact, as light scattering by bacterial cell suspensions appears white and is therefore largely wavelength-independent over the visible light range. However, LED colour did affect some automatic cameras as colour balance 
features on smartphones attempted to optimise images for even colour intensity potentially distorting image intensity; with such cameras white LED illumination may be preferable.

Label-free smartphone bacterial detection is clearly feasible using direct darkfield imaging of light scattering by bacterial cell suspensions in MCF, allowing quantitation without addition of dyes or probes. We defined key parameters (Table 1) to maximise signal (light scattered by bacteria) and minimise noise (from glare) and found that label-free bacterial measurement in microfluidic devices is only possible with carefully designed illumination geometry. The parameter that had the biggest impact on signal and noise was illumination angle, with lowest angles, $\vartheta=5^{\circ}$, showing high noise, preventing clear bacterial quantitation and the signal:noise intensity of scattered light peaking at an illumination angle of $15^{\circ}$ (Figure 1D). Light scattering and reflection occur not only from bacteria, but also from the device, especially at interfaces between materials of differing refractive index (device-air and device-water), and from light scattering by the device material itself. Using a microfluidic device fabricated from a fluoropolymer material that has a refractive index matched to the aqueous sample simplifies this by eliminating the device-water reflection and diffraction.

\subsection{Sensitivity of bacterial measurement is improved following bacterial sedimentation within capillaries}

One remarkable observation was that when MCF test strips were imaged horizontally, it was possible to directly observe bacterial sedimentation within the device (Figure 2) and improve the detection of bacterial suspensions. E. coli suspensions of 0.1-1.0 OD600 were filled into parallel microcapillaries within the same MCF test strip. The scatter intensity was proportional to cell density. Initially, the lowest cell density showing clear scattering at 0.34 OD600 was $2.8 \times 10^{5}$ CFU/capillary with volume of $1 \mu \mathrm{L}$. Sequential images showed sedimentation within the capillaries, with intensity increasing whilst line width reduced (Figure 2A). After sedimentation, bacterial concentrations as low as 0.1 OD 600 were clearly detected corresponding to a cell density of $8 \times 10^{4}$ CFU/capillary. The intensity reached after sedimentation was even higher for larger capillary diameter, although this took longer to settle, plateauing after 40 minutes (Figure 2B).

Using only the smartphone camera plus single LED light source, with $1 \mu \mathrm{L}$ sample volumes and a pathlength of only $0.2 \mathrm{~mm}$ (compared to $10 \mathrm{~mm}$ for conventional spectrophotometer), cell densities as low as 0.1 OD600 could be detected. Whilst this label-free technique still requires relatively high cell densities with the minimum detectable concentration being $8 \times 10^{7} \mathrm{CFU} / \mathrm{mL}$, by using the microfluidic design to allow sedimentation to increase signal we achieved similar measurement range to the ubiquitous microbiology laboratory method using a conventional spectrometer to make turbidity measurements that quantify attenuation of collimated light by the bacterial cell suspension. While spectrophotometer measurements typically use a sample volume of $0.1-1 \mathrm{~mL}$, the microcapillary device uses only $1 \mu \mathrm{L}$ per capillary. Although the overall concentration of bacteria did not change, as bacteria settled to the bottom of the capillaries the local concentration increased significantly and therefore increased the intensity of light scattering that could be imaged. 
Sedimentation of bacteria by gravity has been observed in MCF strips, using immunocapture of $E$. Coli in MCF, and demonstrates that higher number of $E$. Coli are captured in the lower $35 \mu \mathrm{m}$ section of $200 \mu \mathrm{m}$ diameter capillaries after sedimentation (Alves and Reis, 2019a). The line thickness of the bacterial sample in the same microcapillary film reduced from $200 \mu \mathrm{m}$ to below 50 $\mu \mathrm{m}$ after 30 minutes (Figure $2 \mathrm{~B}$ ). Without sedimentation, the lowest bacterial concentration that can be measured was 0.34 OD600, but within 30 minutes a further increase in detection sensitivity allowed clear detection down to 0.1 OD600. Even with this increased sensitivity, label-free detection is less sensitive than dye-labelled detection (e.g. chlorophenol red- $\beta-D-$ galactopyranoside) or other amplified systems where detection of $10^{3}$ or $10^{4} \mathrm{CFU} / \mathrm{mL}\left(1 \times 10^{-4}\right.$ or $1 \times 10^{-5}$ OD) can be achieved (Chen, 2015, Shabani, 2013). However, many microbiological techniques rely on turbidity measurements of cell concentrations in this 0.1-1.0 OD600 range which is the range measured by the spectrophotomer (Figure $2 \mathrm{C}$ ), and we propose our system is a viable alternative to spectrometer measurements. 

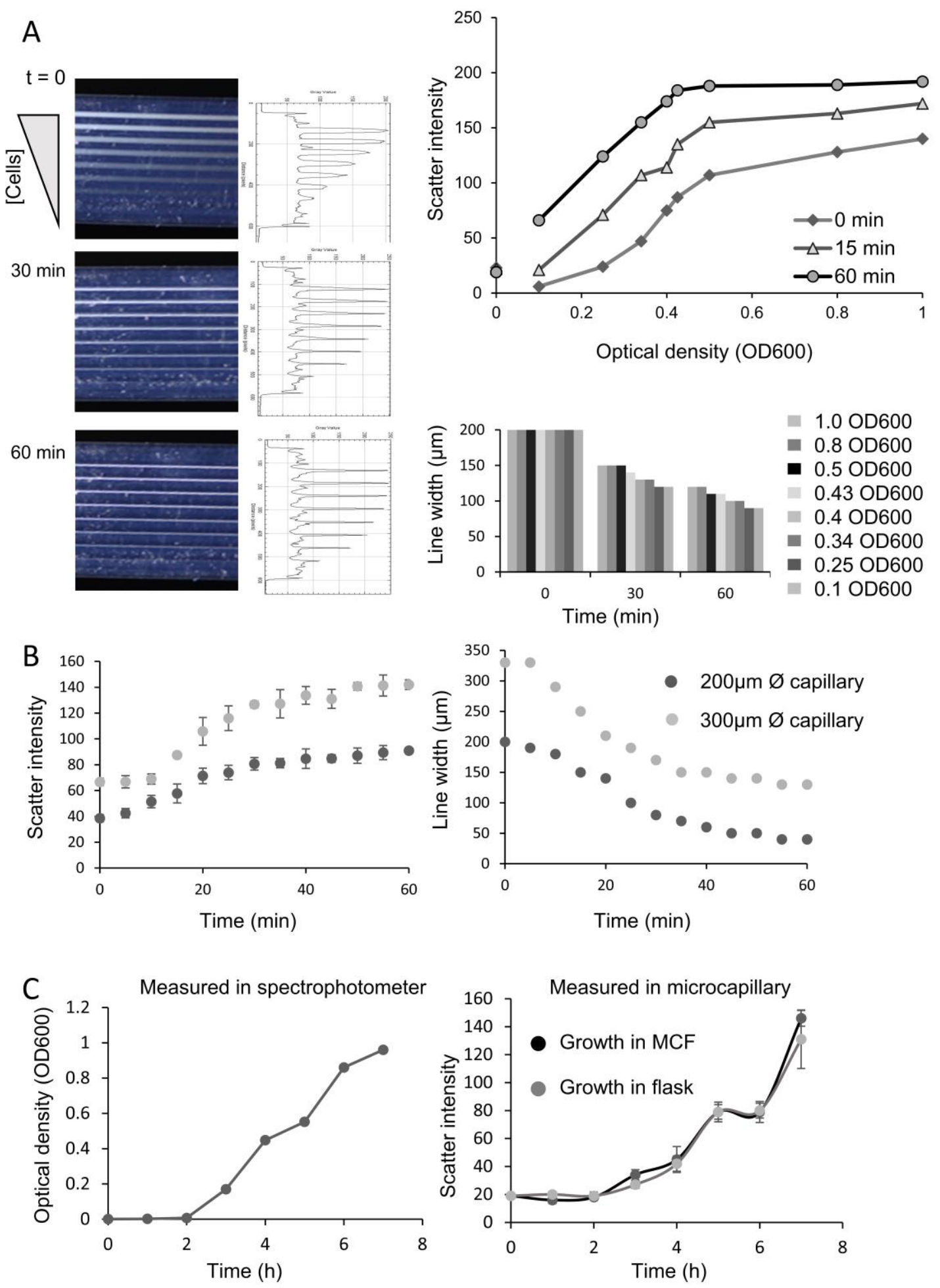

Figure 2: Direct observation of bacterial sedimentation and growth in MCF by light scattering.

A) Sedimentation of eight concentrations of $E$. coli were imaged in $200 \mu \mathrm{m}$ internal diameter MCF strips, with the top and bottom capillary being filled with water alone, and highest bacterial density in the topmost capillary were imaged using a white LED. Scattering intensity increased, and width 
of scattering signal decreased with time as bacteria sedimented to the bottom of the microcapillaries. Light scatter intensity was plotted against cell density (measured as OD600) without sedimentation and after 30 or 60 minutes, showing increased sensitivity with sedimentation. B) Bacterial sedimentation was observed over time within two different microcapillary diameters $(200 \mu \mathrm{m}$ and $300 \mu \mathrm{m})$ using E. coli at 0.3 OD. Data indicates the mean of 20 replicate microcapillaries C) Growth curves were measured in parallel using cuvette in spectrophotometer vs within MCF and comparing cell growth kinetics in flask vs within 20 replicate microcapillaries. All error bars are plotted and indicate the standard deviation, in some cases this is smaller than the symbol size.

\subsection{Portable smartphone detection of growth kinetics and bacteriophage lysis}

Bacterial growth was monitored in MCF vs cuvettes, comparing darkfield scattering intensity with OD measurements in a spectrophotometer. Similar growth kinetics were observed when grown in a shaker flask - either measured in cuvette or transferred to MCF for measurement - or grown directly and measured in MCF (Figure 2C), indicating both that measurement between cuvette and MCF is comparable, and E. coli growth is similar in MCF to shaken flask, demonstrating that labelfree growth kinetics can be measured in microfluidics. A major advantage of label-free bacterial cell detection is for the detection of bacterial lysis, for example, by phage. This cannot easily be monitored using metabolic growth dyes, because the dye can be converted by viable bacteria prior to lysis.

One critical purpose of this device was to detect lytic fragmentation of target bacteria in microfluidic devices to determine bacteriophage host specificity. We designed and 3D printed a prototype portable smartphone bacteriophage lysis reader (Figure 3A), using the optimised parameters for darkfield bacterial scatter imaging. When bacterial target cell suspensions were taken up into MCF capillaries loaded with phage and incubated, no light scattering signal was seen (Figure 3B-C). This demonstrates that smartphone imaging with darkfield illumination can detect bacterial lysis in microdevices. To determine if host specificity could be rapidly determined with this system, two strains of $E$. coli were tested. As expected, when permissive $E$. coli $B$ strain were tested in T2 phage loaded MCF test strips, light scattering was lost in contrast to the T2 resistant E.coli 25922 strain that showed high scattering signal in the presence of T2 phage (Figure 3B-C). During incubation, strips were kept in the same conformation to allow bacterial sedimentation throughout the experiment, increasing signal intensity of the bacteria. This also minimised any changes in light scattering due to time to image. 

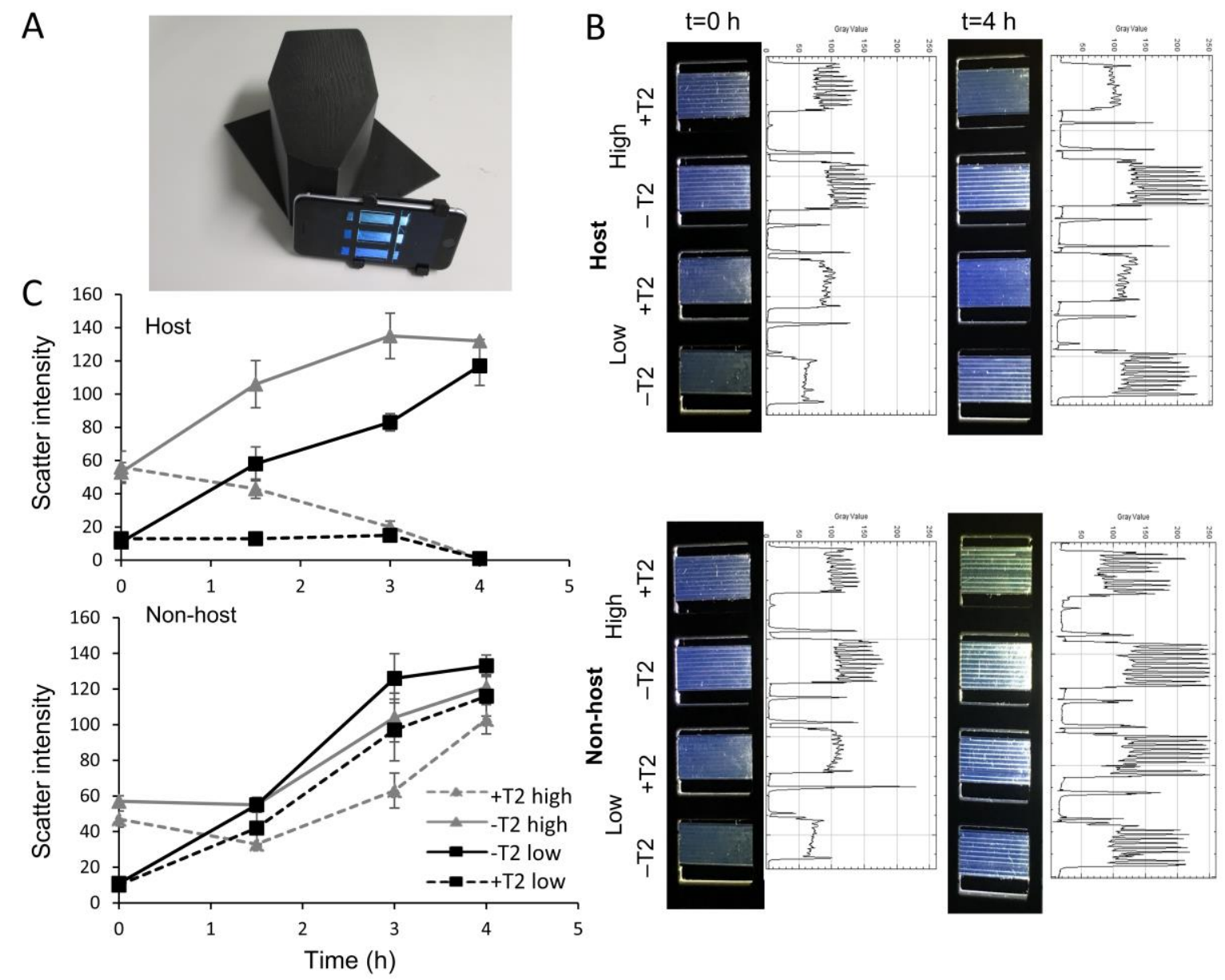

Figure 3: Detection of growth inhibition and lysis by T2 bacteriophage in MCF allows host specificity to be determined by smartphone.

A) Illustration of 3D printed prototype "Phageoscope", a smartphone-compatible darkfield bacterial light scattering measurement device. This offers optimal illumination with a single white LED and combination of light barriers to eliminate unwanted reflections, a holder for microfluidic devices in the centre, and a smartphone clip to position the camera for imaging into the box. B) Images of sets of 4 test strips in the Phageoscope with an iPhone 6S, of tests strips with the indicated combination of bacterial strain (host $=$ E.coli B strain, non-host $=$ E.coli 25922) and T2

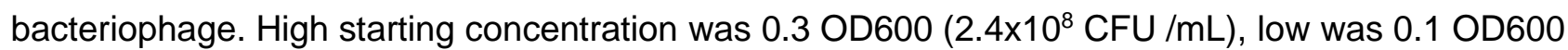
( $\left.8 \times 10^{7} \mathrm{CFU} / \mathrm{mL}\right)$. C) Plot of scatter intensity for strips in B indicating mean of 10 replicate capillaries. All error bars are shown and represent one standard deviation. Data are representative of at least 3 independent repeats. 
In many important microbiology assays (e.g. antibiotic susceptibility testing), bacterial inoculum has a significant impact on results (Smith and Kirby, 2018). We therefore evaluated phage lysis assays with high or low bacterial starting concentrations, with the high concentration being clearly visible by light scattering at the start. Varying the starting concentration did not change the outcome and an absence of light scattering was always clear when phage matched host. This observation may be useful when testing environmental or clinical samples directly as normalisation of bacterial concentration prior to testing is time consuming and laborious. Lysis can still be detected at high starting cell density as bacteriophages replicate much faster than bacteria (Carlton,1999) and the lytic cycle leads to degradation of target cells eliminating the light-scattering particles. This observation is extremely important for the rapid detection of phage lysis. Many devices depend on differentiation between a bacterial growth curve with and without phage, therefore the detection speed is constrained by bacterial growth rate. However, by starting with a high concentration of bacteria, the detection rate becomes dependent only on the phage lysis kinetics which can be far faster. This has been reported when using optical density measurements of phage lysis, which identified that a higher bacterial starting density reduced the time to phage lysis detection (Rajnovic et al., 2019). In our label-free microfluidic system, differential light scatter intensity showed evidence of phage activity as early as after $1.5 \mathrm{~h}$ incubation, but full lysis and elimination of light scattering signal was complete at $4 \mathrm{~h}$ (Figure $3 \mathrm{C}$ ). Further work to incorporate a fully automated time-lapse imaging setup is now justified to further decrease time-to-result of lysis detection. Increasing the resolution of the growth curves will allow differentiation between bacterial growth and lysis earlier.

It is important to be able to rapidly determine if a target pathogen is a lytic host for a therapeutic phage prior to treatment. This proof-of-concept shows that phage can be loaded within MCF devices and lysis detected with a range of target cell densities, suggesting this method could be used as a companion diagnostic for bacteriophage therapy. Further work to characterise and optimise the loading process to quantify and stabilise bacteriophage within the MCF, and to load panels of different bacteriophage with distinct host specificity, is justified. Ultimately, validation will be required for specific therapeutic applications of therapeutic phage to treat specific infections such as hospital-acquired $S$. aureus infection.

\section{Conclusions}

We demonstrate for the first time that label-free microfluidic bacterial detection can be used to determine host specificity for lytic bacteriophage in a portable device using smartphone imaging of light scattering from bacteria illuminated with a single LED.

Digital imaging of MCF in darkfield illumination allowed measurement of bacteria for analytical microbiology such as bacterial growth kinetics, sedimentation and phage lysis of both low and high bacterial cell densities. The major parameters affecting measurement of bacteria in a microfluidic device by light scattering and darkfield imaging were defined, and the optimum illumination angle 
identified as $15^{\circ}$, with elimination of unwanted light reflected or diffracted by the device, holder or container being critical to sensitivity. We propose that microcapillaries should be incubated horizontally for as imaging to allow bacterial sedimentation that increases scattering intensity and thus significantly increases analytical sensitivity. Likewise, illumination should be offset in a horizontal plane to reduce reflections by the curved sides of the device.

Comparison with other microfluidic devices is now justified to identify how important refractive index matching and device geometry is for cell measurement by light scattering. While microfluidic devices have been developed that measure both absorbance and light scattering in bacterial and other biological samples, many of these remain low throughput or require specialised equipment (Strzelak et al., 2016, Strzelak et al., 2020, Keays et al., 2016, Sun et al., 2019). Many of these devices test a single sample can be tested, whereas our digital camera setup can image multiple at once ( 5 strips each with 10 capillaries i.e. 50 conditions per image). Furthermore, no pumps or fluidic controllers are required, with the sample simply drawn up into 10 microcapillaries by capillary action.

Having demonstrated proof-of-concept and the potential of label-free darkfield imaging for miniaturising analytical microbiology, such as companion diagnostics for advanced biological therapeutics in the treatment of bacterial infections, further miniaturisation is now possible retaining the core requirements of the 3D printed prototype, and evaluation with a larger range of hosts and phage is justified. 


\section{References}

ABRÀMOFF, M. D., MAGALHÃES, P. J. \& RAM, S. J. 2004. Image processing with ImageJ. Biophotonics international, 11, 36-42.

ALTAMIRANO, F. L. G. \& BARR, J. J. 2019. Phage therapy in the postantibiotic era. Clinical microbiology reviews, 32, e00066-18.

ALVES, I. P. \& REIS, N. M. 2019a. Immunocapture of Escherichia coli in a fluoropolymer microcapillary array. Journal of Chromatography A, 1585, 46-55.

ALVES, I. P. \& REIS, N. M. 2019b. Microfluidic smartphone quantitation of Escherichia coli in synthetic urine. Biosens Bioelectron, 145, 111624.

BARBOSA, A. I., GEHLOT, P., SIDAPRA, K., EDWARDS, A. D. \& REIS, N. M. 2015. Portable smartphone quantitation of prostate specific antigen (PSA) in a fluoropolymer microfluidic device. Biosens Bioelectron, 70, 5-14.

CHEN, J., ALCAINE, S.D., JIANG, Z., ROTELLO, V.M. AND NUGEN, S.R. 2015. Detection of Escherichia coli in drinking water using $T 7$ bacteriophage-conjugated magnetic probe. Anal. Chem., 87, 8977-8984.

COX, C. R., JENSEN, K. R., MONDESIRE, R. R. \& VOORHEES, K. J. 2015. Rapid detection of Bacillus anthracis by gamma phage amplification and lateral flow immunochromatography. J Microbiol Methods, 118, 516.

DEBARBIEUX, L., LEDUC, D., MAURA, D., MORELLO, E., CRISCUOLO, A., GROSSI, O., BALLOY, V. \& TOUQUI, L. 2010. Bacteriophages can treat and prevent Pseudomonas aeruginosa lung infections. J Infect Dis, 201, 1096-104.

EDWARDS, A. D., REIS, N. M., SLATER, N. K. \& MACKLEY, M. R. 2011. A simple device for multiplex ELISA made from melt-extruded plastic microcapillary film. Lab Chip, 11, 4267-73.

EL HADDAD, L., HARB, C. P., GEBARA, M. A., STIBICH, M. A. \& CHEMALY, R. F. 2018. A Systematic and Critical Review of Bacteriophage Therapy Against Multidrug-resistant ESKAPE Organisms in Humans. Clinical Infectious Diseases, 69, 167-178.

FAROOQ, U., YANG, Q., ULLAH, M. W. \& WANG, S. 2018. Bacterial biosensing: Recent advances in phagebased bioassays and biosensors. Biosens Bioelectron, 118, 204-216.

FELIP, M., ANDREATTA, S., SOMMARUGA, R., STRASKRÁBOVÁ, V. \& CATALAN, J. 2007. Suitability of flow cytometry for estimating bacterial biovolume in natural plankton samples: comparison with microscopy data. Applied and environmental microbiology, 73, 4508-4514.

HINKLEY, T. C., SINGH, S., GARING, S., LE NY, A.-L. M., NICHOLS, K. P., PETERS, J. E., TALBERT, J. N. \& NUGEN, S. R. 2018. A phage-based assay for the rapid, quantitative, and single CFU visualization of E. coli (ECOR\# 13) in drinking water. Scientific reports, 8, 1-8.

HOPPENSTEADT, D. A. \& MOLNAR, J. A. 2020. 42 - Hemostasis and coagulation instrumentation. In: KEOHANE, E. M., OTTO, C. N. \& WALENGA, J. M. (eds.) Rodak's Hematology (Sixth Edition). St. Louis (MO): Content Repository Only!

HUANG, X., XU, D., CHEN, J., LIU, J., LI, Y., SONG, J., MA, X. \& GUO, J. 2018. Smartphone-based analytical biosensors. Analyst, 143, 5339-5351.

HUSSAIN, M., LV, M., XU, J., DONG, X., WANG, T., WANG, Z., WANG, W., HE, N., LI, Z. \& LIU, B. Rapid Identification of Pathogens based on MIE Light Scattering and Machine Learning Approach. 2019 IEEE International Symposium on Medical Measurements and Applications (MeMeA), 26-28 June 2019 2019. 1-5.

JO, Y., JUNG, J., KIM, M. H., PARK, H., KANG, S. J. \& PARK, Y. 2015. Label-free identification of individual bacteria using Fourier transform light scattering. Opt Express, 23, 15792-805.

KEAYS, M. C., O'BRIEN, M., HUSSAIN, A., KIELY, P. A. \& DALTON, T. 2016. Rapid identification of antibiotic resistance using droplet microfluidics. Bioengineered, 7, 79-87.

KRAKER, M. E. A., STEWARDSON, A.J. AND HARBARTH, S. 2016. Will 10 Million People Die a Year due to Antimicrobial Resistance by 2050? PLoS Med, 13(11). 
MCBIRNEY, S. E., TRINH, K., WONG-BERINGER, A. \& ARMANI, A. M. 2016. Wavelength-normalized spectroscopic analysis of Staphylococcus aureus and Pseudomonas aeruginosa growth rates. Biomedical optics express, 7, 4034-4042.

MYERS, J. A., CURTIS, B. S. \& CURTIS, W. R. 2013. Improving accuracy of cell and chromophore concentration measurements using optical density. BMC biophysics, 6, 4-4.

NEEDS, S. H., DIEP, T. T., BULL, S. P., LINDLEY-DECAIRE, A., RAY, P. \& EDWARDS, A. D. 2019. Exploiting open source 3D printer architecture for laboratory robotics to automate high-throughput time-lapse imaging for analytical microbiology. PLoS One, 14, e0224878.

PIVETAL, J., PEREIRA, F. M., BARBOSA, A. I., CASTANHEIRA, A. P., REIS, N. M. \& EDWARDS, A. D. 2017. Covalent immobilisation of antibodies in Teflon-FEP microfluidic devices for the sensitive quantification of clinically relevant protein biomarkers. Analyst, 142, 959-968.

POLANCO, E. R., WESTERN, N. \& ZANGLE, T. A. 2018. Fabrication of Refractive-index-matched Devices for Biomedical Microfluidics. Journal of visualized experiments : JoVE, 58296.

RAJNOVIC, D., MUÑOZ-BERBEL, X. \& MAS, J. 2019. Fast phage detection and quantification: An optical density-based approach. PLOS ONE, 14, e0216292.

REIS, N. M., PIVETAL, J., LOO-ZAZUETA, A. L., BARROS, J. M. \& EDWARDS, A. D. 2016a. Lab on a stick: multianalyte cellular assays in a microfluidic dipstick. Lab Chip, 16, 2891-9.

REIS, N. M., PIVETAL, J., LOO-ZAZUETA, A. L., BARROS, J. M. S. \& EDWARDS, A. D. 2016b. Lab on a stick: multianalyte cellular assays in a microfluidic dipstick. Lab on a Chip, 16, 2891-2899.

SHABANI, A., MARQUETTE, C.A., MANDEVILLE, R. AND LAWRENCE M.F. 2013. Magnetically-assisted impedimetric detection of bacteriausing phage-modified carbon microarrays. Talanta, 116, 10471053.

SHVAlOV, A. N., SUROVTSEV, I. V., CHERNYSHEV, A. V., SOINI, J. T. \& MALTSEV, V. P. 1999. Particle classification from light scattering with the scanning flow cytometer. Cytometry, 37, 215-20.

SMITH, K. P. \& KIRBY, J. E. 2018. The Inoculum Effect in the Era of Multidrug Resistance: Minor Differences in Inoculum Have Dramatic Effect on MIC Determination. Antimicrobial Agents and Chemotherapy, 62, e00433-18.

STRZELAK, K., MALASUK, C., OKI, Y., MORITA, K. \& ISHIMATSU, R. 2020. 3D printed silicone platforms with laser-scattering protein detection under flow analysis conditions as a development of Silicone Optical Technology (SOT). Microchemical Journal, 157, 104936.

STRZELAK, K., MISZTAL, J., TYMECKI, Ł. \& KONCKI, R. 2016. Bianalyte multicommutated flow analysis system for microproteinuria diagnostics. Talanta, 148, 707-711.

SUN, Q., ZHENG, W., LIN, C. \& SHEN, D. 2019. A Low-Cost Micro-Volume Nephelometric System for Quantitative Immunoagglutination Assays. Sensors (Basel, Switzerland), 19, 4359.

SWEENEY, R. E., BUDIMAN, E. \& YOON, J. Y. 2017. Mie scatter spectra-based device for instant, contact-free, and specific diagnosis of bacterial skin infection. Sci Rep, 7, 4801.

TJHUNG, K. F., BURNHAM, S., ANANY, H., GRIFFITHS, M. W. \& DERDA, R. 2014. Rapid enumeration of phage in monodisperse emulsions. Anal Chem, 86, 5642-8.

VAN BELKUM, A., BACHMANN, T. T., LÜDKE, G., LISBY, J. G., KAHLMETER, G., MOHESS, A., BECKER, K., HAYS, J. P., WOODFORD, N. \& MITSAKAKIS, K. 2019. Developmental roadmap for antimicrobial susceptibility testing systems. Nature Reviews Microbiology, 17, 51-62.

WALTHAM, C., BOYLE, J., RAMEY, B. \& SMIT, J. 1994. Light scattering and absorption caused by bacterial activity in water. Appl Opt, 33, 7536-40.

WANG, D., HINKLEY, T., CHEN, J., TALBERT, J. N. \& NUGEN, S. R. 2019. Phage based electrochemical detection of Escherichia coli in drinking water using affinity reporter probes. Analyst, 144, 1345-1352.

WHO 2014. Antimicrobial resistance: global report on surveillance, World Health Organization.

YU, J. Q., HUANG, W., CHIN, L. K., LEI, L., LIN, Z. P., SER, W., CHEN, H., AYI, T. C., YAP, P. H., CHEN, C. H. \& LIU, A. Q. 2014. Droplet optofluidic imaging for lambda-bacteriophage detection via co-culture with host cell Escherichia coli. Lab Chip, 14, 3519-24. 